\title{
DETERMINAÇÃO DE ÍNDICES BIOMETEOROLÓGICOS DA VIDEIRA 'NIAGARA ROSADA' (Vitis labrusca L.) PODA, EM DIFERENTES ÉPOCAS ${ }^{1}$
}

\author{
FÁBIO VALE SCARPARE², LUIZ ROBERTO ANGELOCCI ${ }^{3}$, JOÃO ALEXIO SCARPARE FILHO ${ }^{4}$, \\ JULIANO QUARTEROLI SILVA ${ }^{5}$, ALESSANDRO RODRIGUES ${ }^{6}$
}

RESUMO- O objetivo deste estudo foi determinar os índices: biometeorológico de Primault (IB), heliotérmico de Huglin (IH), heliotérmico de Geslin (IHG) e as unidades fototérmicas (UF) da cultivar Niagara Rosada, podada em diferentes épocas, no inverno e no verão. O experimento foi realizado em Piracicaba-SP, durante três anos agrícolas, avaliando-se 24 ciclos de produção: 12 com poda de inverno e 12 com poda de verão. $\mathrm{O}$ delineamento experimental utilizado foi o de blocos casualizados, sendo os tratamentos correspondentes a oito datas de poda: 20/julho, 04/agosto, 19/agosto e 03/setembro (inverno) e 01/fevereiro, 15/fevereiro, 02/ março e 16/março (verão). A duração em dias e os valores dos índices IB, IH, IHG e UF foram analisados pelo teste de Tukey ao longo das datas de poda e pelo teste $F$ para constrastes ortogonais para as épocas de poda, ambos a $5 \%$ de probabilidade. Os resultados mostraram que a inclusão do elemento meteorológico insolação ou do fator fotoperíodo à base do conceito térmico não mostrou ser eficaz na determinação de um valor médio único na previsão do ciclo de produção, para videiras podadas em diferentes épocas; nenhum dos índices biometeorológicos estudados é eficiente para a previsão da data de colheita em videiras podadas em diferentes épocas; independentemente da época em que o ciclo se inicia, a média de 120 dias pode ser usada como estimativa da data de colheita das videiras em região de clima Cwa.

Termos para indexação: uva, índice biometeorológico, índice heliotérmico, unidades fototérmicas.

\section{BIOMETEOROLOGICAL INDEXES DETERMINATION FOR GRAPE 'NIAGARA ROSADA' (Vitis labrusca L.) PRUNED IN DIFFERENT SEASONS}

\begin{abstract}
The aim of this study was to determine four biometeorological indexes approach: Primault (P), Heliothermic Huglin Index (HHI), Heliothermic Geslin Index (HGI) and Photothermal Units (PU) for 'Niagara Rosada' cultivar pruned in the winter and summer seasons. The experiment was carried out on 13-year-old plants in Piracicaba, state of São Paulo-Brazil, evaluating 24 production cycles, 12 from the winter pruning and 12 from the summer pruning. The statistical design was comprised of randomized blocks, using the pruning dates as treatment: July 20th, August 4th, August 19th, and September 3rd (winter); February 1st, February 15th, March 2nd, and March 16th (summer). Comparison of the mean values of P, HHI, HGI and PU among pruning dates was evaluated by the Tukey test, and comparison between pruning seasons was made by the $F$ test for orthogonal contrasts, both at the $5 \%$ probability level. The results show that the inclusion of the meteorological element insolation and the photoperiod factor on thermal sum requirement is not proved effective in determining an average value for cycle prediction in vines pruned in different seasons; none of the biometeorological indexes are efficient for harvest prediction in vines pruned in different seasons; independent of the time when the cycle starts, the average of 120 days can be used to estimate the harvest date of vines in climate region Cwa.
\end{abstract}

Index terms: grape, biometeorological index, heliothermal index, photothermal units.

\footnotetext{
${ }^{1}$ (Trabalho 272-12). Recebido em: 09-11-2012. Aceito para publicação em: 18-06-2013.

${ }^{2}$ Pesquisador do Laboratório Nacional de Ciência e Tecnologia do Bioetanol - CTBE/CNPEM, Caixa Postal 6170, 13083-970 Campinas, São Paulo, Brazil, E-mail: fabio.scarpare@bioetanol.org.br

${ }^{3}$ Professor Associado do Departamento de Engenharia de Biossistemas - ESALQ/USP, E-mail: 1rangelo@usp.br

${ }^{4}$ Professor Associado do Departamento de Fitotecnia - ESALQ/USP, Email: jascarpa@usp.br

${ }^{5}$ Assistente de Planejamento - CATI EDR de Limeira, E-mail: quarteroli@gmail.com

${ }^{6}$ Coordenador de Certificação Agrícola do Imaflora, 13426-420 - Piracicaba/SP - E-mail: alessandro@imaflora.org
} 


\section{INTRODUÇÃO}

A viticultura tropical é típica de regiões onde as temperaturas mínimas não são suficientemente baixas para induzir a videira à dormência. A videira cresce continuamente e, com o uso de tecnologia apropriada, é possível a obtenção de duas ou mais colheitas por ano, no mesmo vinhedo. A época de colheita pode ser programada para qualquer dia do ano. Os principais polos de viticultura tropical no Brasil são o Vale do Submédio São Francisco, o noroeste Paulista e o norte de Minas Gerais. Nos últimos anos, a viticultura tropical expandiu-se por vários outros Estados, como Espírito Santo, Mato Grosso do Sul, Mato Grosso, Goiás, Rondônia, Ceará e Piauí (CAMARGO et al., 2011).

As plantas sofrem influências dos diversos elementos meteorológicos, dentre os quais a temperatura, a precipitação pluvial, a radiação solar, o vento e a umidade relativa do ar. Estes elementos interagem com os demais componentes do meio natural, em particular com o solo e com as técnicas agronômicas (RAKOCEVIC; MARTIM, 2010). No estudo das relações entre o desenvolvimento das plantas e o clima, geralmente têm-se usado índices biometeorológicos que foram desenvolvidos com o intuito de possibilitar o planejamento da produção.

Dos diversos índices biometeorológicos desenvolvidos, o conceito do somatório térmico que se baseia somente na temperatura do ar para análise do desenvolvimento vegetal tem sido muito usado em viticultura (PEDRO JÚNIOR et al., 1993). Esse índice, medido na forma de graus-dia, tem apresentado resultados consistentes, principalmente quando aplicado em regiões vitícolas do Hemisfério Norte (NENDEL, 2010), bem como no Brasil, quando aplicado em videiras podadas na época tradicional: fim de inverno (PEDRO JÚNIOR et al., 1993). Contudo, Ferreira et al. (2004) questionam a eficiência desse índice, para a videira, quando ele é aplicado em diferentes condições (ambientes protegidos versus a céu aberto) ou em diferentes locais e épocas em que a poda é realizada. Em regiões de clima subtropical e tropical, em que a aplicação de técnicas de poda permite mais de um ciclo de produção por ano, Scarpare et al. (2012) concluíram que houve diferenças entre os graus-dia computados para plantas que iniciam seu ciclo a partir da poda, em diferentes épocas (inverno e verão) e fases fisiológicas.

A inconsistência dos resultados do somatório térmico levou ao aperfeiçoamento desse índice, incluindo outros elementos ou fatores meteorológicos no cálculo que poderiam influenciar no desenvolvimento da planta. Geslin (1944) desenvolveu um índice heliotérmico para aplicação na cultura do trigo, na França. Esse índice é calculado por meio do somatório térmico e do fotoperíodo. No índice biometeorológico de Primault (1969), originalmente desenvolvido para a cultura do milho, além do somatório térmico, o efeito da insolação e da precipitação pluvial, em relação à capacidade máxima de retenção de água no solo, foram incorporados. Huglin (1978) também desenvolveu um índice heliotérmico, que incluiu o ajuste para latitudes, o qual leva em conta a duração do dia (fotoperíodo), como uma tentativa de melhorar a validade da utilização da soma térmica em videira, tendo observado que, em algumas variedades, houve melhoria na correlação entre a soma de temperatura e a taxa de açúcares nos frutos. Villa Nova et al. (1983) desenvolveram o conceito das unidades fototérmicas que, além de considerar o efeito do somatório térmico, associou o efeito do fotoperíodo no desenvolvimento vegetal, em condições de não estresse hídrico; contudo, não há registros de sua utilização em viticultura.

Em viticultura, a grande maioria dos estudos de exigências climáticas refere- se à utilização do somatório térmico, havendo poucos relatos do emprego de outros índices biometeorológicos para esse fim. Pedro Júnior et al. (1994) determinaram as exigências climáticas utilizando o índice biometeorológico de Primault para a cultivar Niagara Rosada, em JundiaíSP. Para o índice heliotérmico de Huglin, há relatos de seu uso na descrição da aptidão de regiões de cultivo de videiras, principalmente para as usadas na produção de vinho (TONIETTO; CARBONNEAU, 2004; CONCEIÇÃO; TONIETTO, 2005) e por Mandelli (2002) para a cultivar Niagara Branca, em Bento Gonçalves-RS. Em todos esses estudos, esses índices foram sempre determinados para o ciclo de produção tradicional, ou seja, poda de inverno.

No Estado de São Paulo, tem-se realizado a poda de produção, para a uva 'Niagara Rosada', em duas estações: no inverno e no verão. A poda de inverno faz com que a colheita dos frutos ocorra no fim da primavera ou no início do verão, caracterizado como período de alta demanda de mercado, enquanto na poda de verão a colheita ocorre no fim do outono ou no início do inverno, também chamada de safrinha. Nas duas estações, as podas são realizadas em várias datas, visando a escalonar a disponibilidade do produto no mercado, evitando assim baixos preços devido à oferta excessiva; além de melhor organizar a mão de obra necessária para a colheita e outras práticas de manejo.

Tendo em vista a importância de se conhecer as exigências climáticas da videira nas condições específicas de cultivo de Piracicaba, o objetivo deste 
estudo foi determinar o índice biometeorológico de Primault (IB), o índice heliotérmico de Huglin (IH), o índice heliotérmico de Geslin (IHG) e as unidades fototérmicas (UF) da cultivar Niagara Rosada, podada em diferentes épocas: no inverno e no verão.

\section{MATERIAL E MÉTODOS}

$\mathrm{O}$ experimento foi realizado em área experimental do Departamento de Produção Vegetal da ESALQ-USP, no município de Piracicaba-SP, em Argissolo Vermelho eutrófico, durante três anos agrícolas (2005/2006, 2006/2007 e 2007/2008). O tipo climático dessa região é o Cwa, tropical de altitude, segundo a classificação climática de Köppen. Foi utilizada a uva para mesa, cultivar Niagara Rosada (Vitis labrusca L.), com 13 anos de idade, enxertada na cultivar Ripária do Traviu (Vitis riparia) X (Vitis rupestris X Vitis cordifolia), podada em duas épocas, sendo avaliados 24 ciclos de produção: 12 com poda de inverno e 12 com poda de verão.

a) Poda de inverno (fase de mobilização de reservas): executada no inverno, com uma ou duas gemas, e a colheita ocorrendo no fim da primavera e no início de verão. O desenvolvimento inicial da videira ocorre em época de temperaturas amenas e fotoperíodo crescente; a maturação e a colheita dos frutos ocorrem em época de elevadas temperaturas e menor quantidade de horas de luz direta, insolação em virtude da maior nebulosidade nessa estação (Figura 1). É também denominada poda seca, porque as plantas estarão desfolhadas nessa época.

b) Poda de verão (fase de acúmulo de reservas): realizada no verão, com três a quatro gemas, e a colheita ocorrendo no fim do outono e no início do inverno. Esse ciclo de produção é caracterizado por apresentar temperaturas elevadas e fotoperíodo decrescente, no início do desenvolvimento das plantas, e temperaturas amenas e maior quantidade de horas de luz direta, insolação em virtude da menor nebulosidade no período de colheita (Figura 1). Também é denominada como poda verde, porque as plantas se apresentam enfolhadas na ocasião da poda de produção.

Com o intuito de uniformizar a brotação das gemas, após a realização das podas, as gemas foram pinceladas com solução de cianamida hidrogenada a $5 \%$.

O delineamento experimental utilizado foi o de blocos casualizados, sendo os tratamentos representados pelas oito datas de poda: 20/julho, 04/agosto, 19/agosto, 03/setembro, 01/fevereiro, 15/fevereiro, 02/março e 16/março. A verificação da normalidade dos dados foi realizada por meio do teste de Shapiro-Wilk, a 5\% de probabilidade, e para o estudo de homogeneidade de variância, o método de Box-Cox. Para a análise de variância, foi utilizado o teste de Tukey, ao nível de 5\% de probabilidade, para comparar as médias entre as datas de poda. A comparação entre as épocas de poda (poda de inverno versus poda de verão) foi realizada pelo teste $F$, para contrastes ortogonais, ao nível de $5 \%$ de probabilidade. A parcela experimental foi composta de 10 plantas, em espaçamento de 2,0 m x 1,0 m, sustentadas no sistema de espaldeira.

Durante todo o ciclo de produção, houve o monitoramento da água disponível no solo por meio de três tensiômetros instalados a $0,2 \mathrm{~m}$ de profundidade. A irrigação por sulco foi aplicada quando o potencial matricial de água do solo atingia valores entre -130 e -200 hPa, sendo fornecida água até se atingir valores em torno do potencial mátrico próximos à capacidade de campo, assumido como sendo da ordem de $-70 \mathrm{hPa}$ para o solo do experimento.

As variáveis analisadas foram a duração em dias e os valores de quatro índices: Biometeorológico de Primault (IB), Heliotérmico de Huglin (IH), Heliotérmico de Geslin (IHG) e das Unidades Fototérmicas (UF) ao longo do ciclo de produção, poda-colheita $(P-C)$, e os períodos que compõem esse ciclo: poda-brotação $(P-B)$, brotação-florescimento $(B-F)$, florescimento-início de maturação dos frutos $(F-M)$ e início de maturação dos frutos-colheita ( $M$ $C)$. Devido ao fato de a poda não ser considerada um estádio fenológico, o ciclo brotação-colheita $(B-C)$ foi também analisado.

Os períodos avaliados foram baseados de acordo com os estádios fenológicos propostos por Lorenz et al. (1994), considerando-se como data de brotação o momento em que $50 \%$ das plantas apresentaram gemas induzidas no estádio de ponta verde (estádio 07); florescimento, quando metade das plantas apresentou mais de $50 \%$ de flores abertas (estádio 65); início de maturação, quando metade das plantas apresentou bagas com início de coloração típica da 'Niagara Rosada' (estádio 81); e colheita, quando mais de $50 \%$ dos cachos de cada planta haviam sido colhidos. A colheita foi seletiva, considerando-se como ponto de colheita quando as bagas apresentavam frutos com $15^{\circ}$ brix. A medida do teor de sólidos solúveis foi realizada a campo, com refratômetro manual, selecionando-se, de forma aleatória, 3 frutos na porção superior dos cachos.

Os elementos meteorológicos necessários para o cálculo dos índices foram obtidos da Estação Meteorológica da Universidade de São Paulo, Câmpus "Luiz de Queiroz" da USP (latitude $22^{\circ}$ 42' 30" sul; longitude $47^{\circ} 38^{\prime}$ ' 00 ' oeste e altitude 
546 metros), distantes cerca de $600 \mathrm{~m}$ do local do experimento.

A determinação do IB foi realizada de acordo com Primault (1969).

$$
I B=G D+i \sum I+p \sum P k
$$

em que: $I$ é o total de insolação diária (horas); $P$ é o total de precipitação considerando um fator máximo de água disponível ao vegetal no solo (mm); $i, p$ são coeficientes de ponderação variáveis a serem determinados; $k$ é o fator máximo de água disponível no solo (mm), e GD são os graus-dia acumulados no período $\left({ }^{\circ} \mathrm{C} \mathrm{d}\right)$. Devido ao fato de não ter havido deficiência hídrica durante o estudo, o fator da precipitação pluvial foi desconsiderado, resultando na fórmula proposta por Pedro Júnior et al. (1994).

$$
I B=\sum G D+0,4 \sum I
$$

A determinação do IH foi calculada segundo a fórmula (HUGLIN, 1978):

$$
I H=\sum \frac{(\text { Tmed }-T b)+(T x-T b)}{2} \times k
$$

em que: Tmed é a temperatura média diária; $T b$ é a temperatura-base; $T x$ é a temperatura máxima, e $k$ é o coeficiente multiplicador que expressa o comprimento do dia em relação à latitude. Para latitudes entre $40^{\circ} 01^{\prime}$ ' a $42^{\circ} 00^{\prime}, k=1,02$; entre $42^{\circ} 01$ ' a $44^{\circ} 00^{\prime}, k=1,03$; entre $44^{\circ} 01^{\prime}$ a $46^{\circ} 00^{\prime}, k=1,04$; entre $46^{\circ} 01^{\prime}$ a $48^{\circ} 00^{\prime}, k=1,05$; e entre $48^{\circ} 01^{\prime}$ ' a $50^{\circ} 00^{\prime}, k=1,06$. Para latitudes menores de $40^{\circ}$, o coeficiente multiplicador assume valor unitário.

A determinação do IHG foi calculada de acordo com Geslin (1944).

$$
\text { IHG }=\frac{1}{100} \times \sum(\text { Tmed } \times n)
$$

em que: $n$ é o fotoperíodo médio (horas) do período considerado.

As UFs foram determinadas pela aplicação de equação proposta por Villa-Nova et al. (1983).

$$
U F=\frac{(G D)^{\frac{N i}{N i}+1}}{\frac{N f}{N i}+1}
$$

em que: UF é o número de unidades fototérmicas acumuladas no período; GD são os graus-dia acumulados no período $\left({ }^{\circ} \mathrm{C} \mathrm{d}\right) ; N f$ é a duração astronômica do dia (horas e décimo de horas) no fim do período de crescimento, e $N i$ é a duração astronômica do dia (horas e décimo de horas) no início do período de crescimento, sendo as duas últimas variáveis determinadas pela relação:

$$
\begin{aligned}
& N f . \text { ou Ni }=0,133^{*} \operatorname{arcos}\left(-\operatorname{tg} \delta^{*} \operatorname{tg} \varphi\right) \\
& \delta=23,45 \operatorname{sen}\left[\frac{360}{365}\left(D_{j}-80\right)\right]
\end{aligned}
$$

nas equações (6) e (7): $\delta$ corresponde ao valor da declinação solar para aquela latitude; $\phi$ a latitude do local, e $D J$ o dia Juliano $\left(\mathrm{n}^{\circ}\right.$ de ordem a partir de $1^{\circ}$ de janeiro).

O cálculo dos graus-dia utilizados em IB e UF foi realizado segundo as equações propostas:

$$
\begin{array}{cc}
G D= & (T n-T b)+\frac{(T x-T n)}{2}-C \quad(T n>T b) \\
G D=\frac{(T x-T b)^{2}}{2 \times(T x-T n)}-C \quad & (T n<T b) \\
G D=0 & (T x<T b) \\
C=\frac{(T x-T B)^{2}}{2 \times(T x-T n)} \quad(T M>T B)
\end{array}
$$

sendo: $T x$ a temperatura máxima diária $\left({ }^{\circ} \mathrm{C}\right) ; \mathrm{Tn}$ a temperatura mínima diária $\left({ }^{\circ} \mathrm{C}\right) ; \mathrm{Tb}$ a temperatura-base inferior; $T B$ a temperatura-base superior diária, e $C$ a correção da temperatura-base superior.

A temperatura-base inferior adotada foi a de $10^{\circ} \mathrm{C}$, determinada para essa cultivar por Pedro Júnior et al. (1994), enquanto a temperatura-base superior foi a de $30^{\circ} \mathrm{C}$.

\section{RESULTADOS E DISCUSSÃO}

A duração em dias dos ciclos de produção $(P-C$ e $B-C)$ decresceu com o escalonamento da data de poda, quando realizada no inverno, não sendo observada essa mesma tendência em plantas podadas no verão (Tabela 1). Resultados similares para a videira 'Niagara Rosada' foram observados em diferentes locais, no Estado de São Paulo (PEDRO JÚNIOR et al., 1993; PEDRO JÚNIOR et al., 1994). Isso ocorre principalmente pela diferença em dias observada em $F-M$, que é o período de maior duração do ciclo de produção. É nele que ocorre a primeira fase de crescimento dos frutos, em que a atividade fotossintética das plantas é alta. Essa fase é chamada de autossuficiente, pois todos os fotoassimilados pela planta são consumidos para seu desenvolvimento (BORGHEZAN et al., 2012). Nas plantas podadas precocemente, esse período ocor- 
reu nos meses de setembro a outubro, enquanto nas podas mais tardias ocorreu nos meses de outubro a dezembro, meses com temperaturas e fotoperíodos crescentes (Figura 1).

A duração do ciclo de produção delimitado pelos estádios fenológicos, $B-C$, embora tenha apresentado diferenças entre as datas de poda, pelo teste $F$ para contrastes ortogonais, verificou-se que foram similares entre as épocas de poda: inverno e verão (Tabela 2). Portanto, para o ciclo $B-C$, a média de 120 dias obtida dos oito tratamentos pode ser usada como estimativa da data de colheita das videiras conduzidas nessa região, independentemente da época em que o ciclo se inicia. Essa similaridade foi devido ao $F-M$, período esse com mais de 60 dias (Tabela 1), que representa mais de $50 \%$ do ciclo $B-C$ e não apresentou diferença entre as épocas de poda (Tabela 2).

Na determinação dos índices biometeorológicos nos ciclos de produção $(P-C$ e $B-C)$, para todas as datas de poda, independentemente da época em que foram realizadas, observou-se que todos apresentaram variações significativas (Tabela 1). Plantas que iniciaram seu ciclo no inverno demandaram maior energia para atingir a colheita do que plantas que iniciaram seu ciclo no verão, embora os coeficientes de variação apresentados tenham sido baixos, exceção para o índice UF (Tabela 1). Assim, por meio do teste $F$ para contrastes ortogonais, podas no inverno versus poda no verão, foram observadas diferenças entre as épocas de poda para os ciclos de produção $P-C$ e $B-C$ e para todos os períodos que compõem os ciclos, com exceção para $B-F$ nos índices IH e IHG (Tabela 2). Scarpare et al. (2012) relataram a mesma tendência para o somatório térmico medido em graus-dia, em videiras de 'Niagara Rosada' podadas no inverno e no verão, na mesma região.

Pelo conceito do somatório térmico, as variações impostas pelo local de cultivo, escalonamento das épocas e datas de poda não deveriam afetar o valor acumulado ao fim do ciclo (NENDEL, 2010). No entanto, é importante destacar que, além de as condições climáticas no transcorrer de todo o desenvolvimento serem distintas, outra possível causa das diferenças observadas deve estar relacionada com o fato de que o início do ciclo ocorre sob distintas condições fisiológicas. Outra limitação na aplicação de índices biometeorológicos em plantas perenes que passam por repouso hibernal, como a videira, está na identificação de um estádio fenológico que caracterize o início do ciclo vegetativo, ou seja, a saída da dormência e o início da fase da mobilização de reservas, diferentemente das plantas anuais que têm a semeadura como ponto de partida. Como não há nenhum estádio fenológico visível indicando o fim do período de dormência nas videiras, é adotada a técnica cultural (poda) como ponto de partida para o cálculo dos índices biometeorológicos.

Além dos graus-dia, estudos com a determinação de outros índices biometeorológicos que incluem outros elementos meteorológicos em seus cálculos, são escassos para a videira. Pedro Júnior et al. (1994) determinaram valor médio do IB em 1945 , para o ciclo $B-C$ da 'Niagara Rosada', podada no inverno, em Jundiaí-SP, $10 \%$ superior ao obtido neste estudo. Já Mandelli (2002) encontrou valores maiores, com IH de 3.033 do início da brotação ao final da queda das folhas para 'Niagara Branca', podada no inverno, na região de Bento Gonçalves (RS). Valores semelhantes a este estudo foram obtidos por Conceição e Tonietto (2005), no norte de Minas Gerais, para uvas destinadas à elaboração de vinhos (Vitis vinifera L.), com valores entre $1.865 \mathrm{e}$ 2.319 para o ciclo $P$-C.

Independentemente das diferentes condições climáticas e fisiológicas em que as videiras estejam submetidas ao longo do ciclo, é desejável que a determinação de valores médios obtidos por meio de índices biometeorológicos seja a mais uniforme possível. Dessa forma, sua adoção para a previsão do ciclo seria indicada, independentemente das datas ou épocas em que a poda é realizada, ainda que a tomada da data de poda como ponto inicial e da colheita como ponto final da contabilização possa introduzir variabilidade nos índices. Sendo assim, a inclusão do elemento meteorológico insolação ou do fator fotoperíodo à base do conceito térmico não mostrou ser eficaz para a determinação de um valor médio único na previsão do ciclo de produção $(P-C \mathrm{e}$ $B-C)$, para videiras podadas em diferentes épocas: no inverno e no verão. Porém, devido à homogeneidade apresentada dentro das épocas, sugerem-se estudos para a determinação desses índices, para cada época de cultivo da planta.

Dos índices biometeorológicos estudos, o IHG foi o único que mostrou uniformidade para a previsão do ciclo, para plantas que iniciaram seu ciclo no inverno, obtendo 374 para $P-C$ e 336 para $B-C$ (Tabela 1). 
TABELA 1 - Duração em dias e valores médios dos índices Biometeorológicos de Primault(IB), Heliotérmico de Huglin (IH), Heliotérmico de Geslin (IHG) e Unidades Fototérmicas (UF) do ciclo podacolheita $P-C$ e brotação-colheita $B-C$ e períodos: poda-brotação $P-B$, brotação-florescimento $B-F$, florescimento-maturação dos frutos $F-M$ e maturação dos frutos-colheita $M-C$ da videira 'Niagara Rosada', podada em diferentes datas. Piracicaba-SP. Anos agrícolas de 2005/2006, 2006/2007 e 2007/2008.

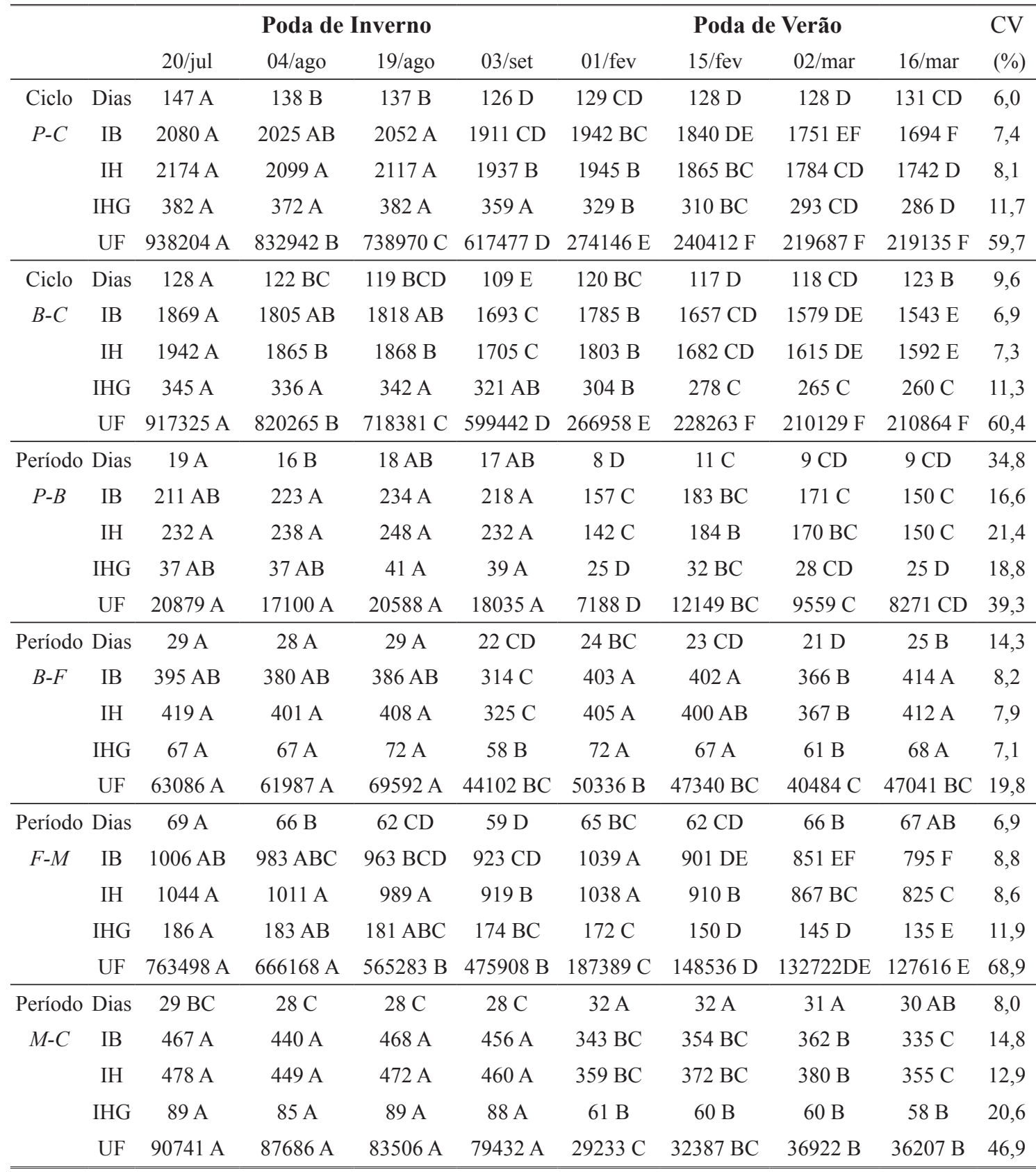

As médias seguidas de mesma letra no sentido horizontal não diferem estatisticamente entre si, ao nível de $5 \%$ de probabilidade, pelo teste de Tukey. 
TABELA 2 - Valores de $F$ obtidos na análise de contraste ortogonais para duração, em dias e índices Biometeorológicos de Primault (IB), Heliotérmico de Huglin (IH), Heliotérmico de Geslin (IHG) e Unidades Fototérmicas (UF) do ciclo poda-colheita $P-C$ e brotação-colheita $B-C$ e períodos: poda-brotação $P-B$, brotação-florescimento $B-F$, florescimento-maturação dos frutos $F-M$ e maturação dos frutos-colheita $M-C$ da videira 'Niagara Rosada', podada em diferentes datas. Piracicaba-SP. Anos agrícolas de 2005/2006, 2006/2007 e 2007/2008.

\begin{tabular}{|c|c|c|c|c|c|}
\hline & \multicolumn{5}{|c|}{ Valor de $F$} \\
\hline & Dias & IB & IH & IHG & UF \\
\hline$P-C$ & $0.0367 *$ & $0.0001 *$ & $0.001 *$ & $0.0001 *$ & $0.0001 *$ \\
\hline$B-C$ & $0.2532^{\text {ns }}$ & $0.0001 *$ & $0.0001 *$ & $0.001 *$ & $0.0001 *$ \\
\hline$P-B$ & $0.0001 *$ & $0.0001 *$ & $0.0001 *$ & $0.0001 *$ & $0.0001 *$ \\
\hline$B-F$ & $0.0001 *$ & $0.0001 *$ & $0.2798^{\mathrm{ns}}$ & $0.4649^{\text {ns }}$ & $0.0001 *$ \\
\hline$F-M$ & $0.3222^{\text {ns }}$ & $0.0001 *$ & $0.0001 *$ & $0.0001 *$ & $0.0001 *$ \\
\hline$M-C$ & $0.0001 *$ & $0.0001 *$ & $0.0001 *$ & $0.001 *$ & $0.0001 *$ \\
\hline
\end{tabular}

n.s. $=$ não significativo; $*$ = significativo ao nível de $5 \%$ de probabilidade.

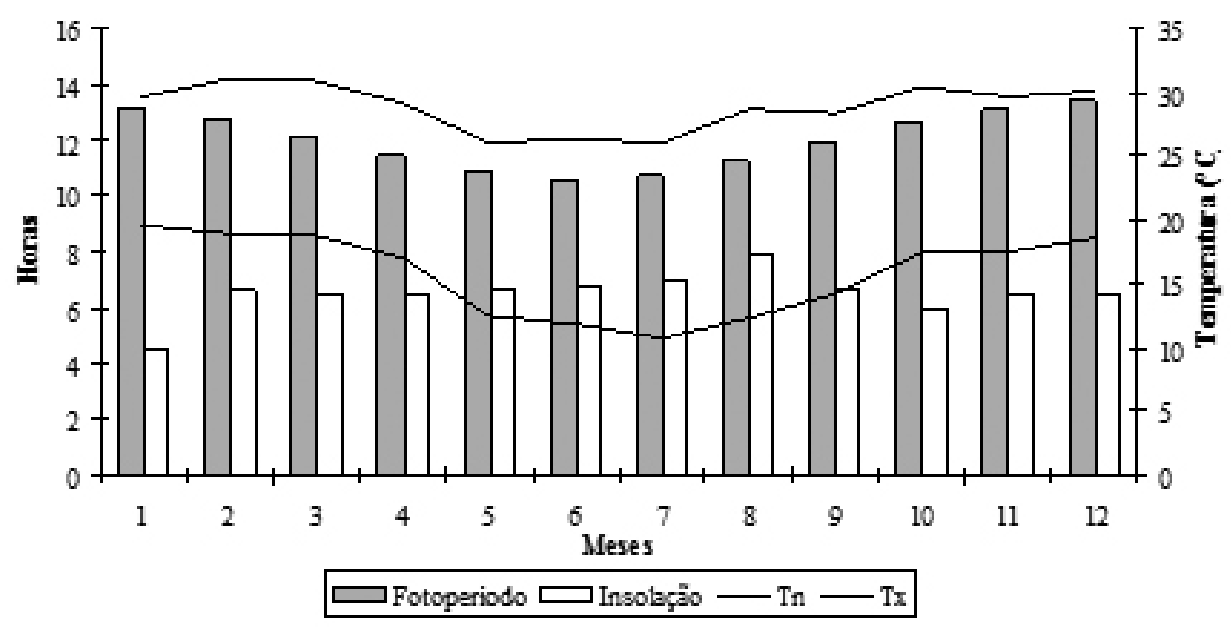

FIGURA 1 - Diagrama climático das médias mensais das temperaturas mínima e máxima do ar em ${ }^{\circ} \mathrm{C}$ (linhas), do fotoperíodo em horas (barras na cor cinza) e insolação em horas (barras na cor branca) construído a partir dos dados obtidos por meio da estação meteorológica da ESALQ/ USP (série de 94 anos: 1917 a 2011).

\section{CONCLUSÕES}

1- Nenhum dos índices biometeorológicos estudados é eficiente para a previsão da data de colheita em videiras 'Niagara Rosada' podadas em diferentes épocas: no inverno e no verão.

2- O ciclo da videira no município de Piracicaba-SP, determinado pelos estádios fenológicos brotação e colheita, pode ser estimado em 120 dias, independentemente da época.

\section{REFERÊNCIAS}

BORGHEZAN, M.; GAVIOLI, O.; VIEIRA, H.J.; SILVA, A.L. Shoot growth of Merlot and Cabernet Sauvignon grapevine varieties. Pesquisa Agropecuária Brasileira, Brasília, v. 47, n. 2, p. 200-207, 2012.

CAMARGO, U. A.; TONIETTO, J.; HOFFMANN, A.; Progressos na viticultura brasileira. Revista Brasileira de Fruticultura, Jaboticabal, v. 33, n.1, p. 144-149, 2011. Edição especial. 
CONCEIÇÃO, M.A.F.; TONIETTO, J. Climatic potential for wine grape production in the tropical north region of Minas Gerais State, Brazil. Revista Brasileira de Fruticultura, Jaboticabal, v. 37, n.3, 404-407, 2005.

FERREIRA, E.A.; REGINA, M.A.; CHALFUN, N.N.J.; ANTUNES, L.E.C. Antecipação de safra para videira 'Niagara Rosada' na região do sul do Estado de Minas Gerais. Ciência Agrotecnologia, Lavras, v. 28 , p. 1.221-1.227, 2004.

GESLIN, H. Étude des lois de croissance d'une plante en fonction des facteurs du climat (température et radiation solaire) contribution a l'étude du climat du blé. Paris: Université de Paris, 1944. $116 \mathrm{p}$.

HUGLIN, P. Nouveau mode d'évaluation des possibilités héliothermiques d'um milieu vitícola. In: SYMPOSIUM INTERNATIONAL SUR L'ECOLOGIE DE LA VIGNE, 1978, Contança. Annales ... Contança: Ministère de I'Agricultura et de I'Industrie Alimentaire, 1978. p.89-98.

LORENZ, D. H.; EICHHORN, K.W; BLEIHOLDER, H.; KLOSE, R.; MEIER, U.; WEBER, E. Phänologische Entwicklungsstadien der Weinrebe (Vitis vinifera L. ssp. Vinifera. Viticulture and Enology Science, Springfield, v.49, p.66-70, 1994.

MANDELLI, F. Relações entre variáveis meteorológicas, fenologia e qualidade da uva na "serra gaúcha"-2002. 196f. 2002. Tese (Doutorado em Fitotecnia) - Faculdade de Agronomia, Universidade Federal do Rio Grande do Sul, Porto Alegre, 2002.

NENDEL, C. Grapevine bud break prediction for cool winter climates. International Journal of Biometeorology, Lisse, v. 54, p. 231-241, 2010.

PEDRO JÚNIOR, M.J.; SENTELHAS, P.C.; POMMER, C.V. Determinação da temperaturabase, graus-dia e índice biometeorológico para da videira 'Niagara Rosada'. Revista Brasileira de Agrometeorologia, Santa Maria, v. 2, p. 51-56, 1994.
PEDRO JÚNIOR, M.J.; SENTELHAS, P.C.; POMMER-MARTINS, F.P.; GALLO, P.B.; SANTOS, R.R.; BOVI, V.; SABINO,J.C. Caracterização fenológica da videira 'Niagara Rosada' em diferentes regiões paulistas. Bragantia, Campinas, v. 52, n. 2, p. 153-160, 1993.

PRIMAULT, B. D'une application pratique des indices biométéorologiques. Agricultural Meteorology, Amsterdam v. 6, n. 2, p. 71-96, 1969.

RAKOCEVIC, M.; MARTIM, S.F. Time series in analysis of yerba-mate biennial growth modified by environment. International Journal of Biometeorology, Lisse, v. 54, p. 1-9, 2010.

SCARPARE, F.V.; SCARPARE FILHO, J.A.; RODRIGUES, A.; REICHARDT, K.; ANGELOCCI, L.R. Growing degree-days for the 'Niagara Rosada' grapevine pruned in different seasons. International Journal of Biometeorology, Lisse, v. 56, p 823-830, 2012.

TONIETTO, J.; CARBONNEAU, A. A multicriteria climatic classification system for grapegrowing regions worldwide. Agricultural and Forest Meteorology, Amsterdam, v. 124, n. 1-2, p. 81-97, 2004.

VILLANOVA, N. A.; CARRETEIRO, M. V.; SCARDUA, R. Um modelo de avaliação do crescimento de cana-de-açúcar (Saccharum spp.) em termos da ação combinada do fotoperíodo e da temperatura média do ar. In: CONGRESSO BRASILEIRO DE AGROMETEOROLOGIA, 3., 1983, Campinas. Anais ... Campinas: Sociedade Brasileira de Agrometeorologia, 1983. p.31-48. 